\title{
O Fundamento Ético da Crítica de Lacan à Psicanálise Pós- Freudiana
}

\section{The Ethical Foundation of Lacan's Critique of Post-Freudian Psychoanalysis}

\author{
Vinicius Anciães Darriba' (orcid.org/ 0000-0002-9986-6554)
}

\begin{abstract}
Resumo
Mostra-se, neste artigo, que a crítica de Lacan à Psicanálise pós-freudiana, em seus primeiros Seminários, já tinha por fundamento o que ele viria propor segundo uma ética da Psicanálise. Isto é verificado com respeito aos alvos privilegiados dessa crítica, os quais configurariam, assim, um esforço de conciliação da Psicanálise com determinados ideais, contrário ao que, na transmissão efetuada pela obra de Freud, situaria o inédito da experiência por ele inaugurada, articulado por Lacan em termos éticos.
\end{abstract}

Palavras-chave: Psicanálise. Lacan. Ética.

\begin{abstract}
It is shown, in this article, that Lacan's critique of post-Freudian psychoanalysis, in his first Seminars, was already based on what he would propose according to an ethics of psychoanalysis. This is verified with respect to the privileged targets of this critique, which would constitute an effort to reconcile psychoanalysis with certain ideals, which is contrary to what, in the transmission made by Freud's work, would place the unprecedented of the experience inaugurated by him, articulated by Lacan in ethical terms.
\end{abstract}

Keywords: Psychoanalysis. Lacan. Ethics.

1 Universidade do Estado do Rio de Janeiro, Rio de Janeiro, Brasil. E-mail: viniciusdarriba@gmail.com. 


\section{Introdução}

No Ato de Fundação, da Escola Francesa de Psicanálise, Lacan (1964/2003, p. 235) propõe para esta um trabalho que,

no campo aberto por Freud, restaure a sega cortante de sua verdade; que reconduza a práxis original que ele instituiu sob o nome de psicanálise ao dever que lhe compete em nosso mundo; que, por uma crítica assídua, denuncie os desvios e concessões que amortecem seu progresso, degradando seu emprego.

Se a decisão, nesse momento, de fundar uma Escola - em que assume a garantia por sua direção - estabelece um marco no percurso de Lacan, a orientação que vemos imprimir remonta ao que distingue seu ensino desde o início. Ao propor uma crítica assídua aos desvios e concessões que amortecem o progresso da Psicanálise, ele usa o mesmo termo - crítica - com que já intitulava seu procedimento no que concerne "àqueles que se encontram em posição de seguir Freud" (Lacan, 1953-54/1986, p. 25). Igualmente, já era o campo aberto por Freud o suporte estabelecido para essa crítica.

À falta deste remanejamento, com efeito, é possível que não cesse de aumentar a distância entre as teorias dominantes na psicanálise de hoje aquilo a que se chama suas tendências atuais - e a doutrina freudiana, que a meus olhos constitui nada menos que a única formulação conceitual correta da experiência que esta própria doutrina fundou. (Lacan, 1956-57/1995, p. 182)

Finalmente, a associação dessa experiência à verdade já comparece, desde os primeiros Seminários, asseverando a distinção com relação a uma noção de realidade (Lacan, 1953-54/1986, p. 31) que afiançava uma deriva objetivante da Psicanálise, destinada a um enquadre adaptativo. A crítica de Lacan, assim alicerçada, mostra-se particularmente atual quando nos voltamos para a ênfase que passou a ser dada aos procedimentos avaliativos no campo da clínica, pretensamente espelhando o modelo da Medicina Baseada em Evidência (MBE), protótipo de uma cientificidade padrão. A MBE serve de referência, correntemente, à produção de evidência científica, na qual a intenção objetivante, no que concerne à comparação de práticas, resulta na primazia da eficácia. Veremos, adiante, que Lacan não centrou a crítica a que faz referência no fator da eficácia - se algo funciona -, mas sim interroga, culminando no Seminário sobre a ética da Psicanálise (1959-60/1991), a orientação ética que determinada experiência delimita.

Maleval (2012) aponta que o particular da dimensão ética fica de fora, quando se reduz a clínica a técnicas confrontáveis quanto a sua eficácia. Ele tomou em análise o relatório produzido, na França, pelo Institut National de la Santé et de la Recherche Médicale (Inserm, 2004), por encomenda das autoridades governamentais, com a finalidade de subsidiar a regulamentação da prática da psicoterapia no bojo da legislação relativa à política de saúde pública. A discussão de Maleval (2012, p. 149) enfatiza a série de constrangimentos impostos ao estudo, uma meta-análise, pela decisão de se aplicar a ferramenta estatística; decisão metodológica que, no campo das psicoterapias, 
acaba condicionando de modo indubitável o resultado a que se chega. $O$ tratamento estatístico dos dados só é possível supondo que eles derivem de um espaço de equivalência, de medida comum. No caso das psicoterapias, isso impôs a condição de que a eficácia fosse avaliada em relação a sintomas supostamente isoláveis.

A paridade entre eficácia e desaparecimento do sintoma condiciona a clínica a uma norma adaptativa. Tomou-se no estudo, em comparação com as terapias cognitivo-comportamentais e familiares, psicoterapias breves como representantes das terapias psicodinâmicas. Isso porque, ainda para fins estatísticos, era necessário equalizar a duração das intervenções. Além de não equivalerem ao espectro principal da prática da Psicanálise na França e em outros países, as psicoterapias breves, no âmbito da Psicanálise, tomam por base, preponderantemente, os elementos doutrinais que veremos Lacan criticar. No contexto da divulgação midiática do relatório, isso não impediu, contudo, a veiculação da ideia de que a Psicanálise tout court teria sido avaliada.

Apesar dessas ressalvas e de outras, como as assinaladas por um dos especialistas que compunham a equipe responsável pelo estudo (Thurin, 2004), perguntamos, sendo esse um modelo sólido na atualidade, se os psicanalistas se veriam tentados a alinhar sua prática aos princípios segundo os quais se supõe que ela será avaliada. Essa é a questão que aqui nos importa, haja vista a adequação entre o que veremos ter sido alvo de crítica por Lacan e o que os procedimentos de avaliação propostos induziriam. Conforme a perspectiva de Lacan
(1959-60/1991), o que estaria em jogo, nesse caso, seria a própria ética da Psicanálise.

Nos primeiros Seminários, Lacan designou, como objeto de sua crítica, o que nomeou como Psicanálise pós-freudiana, localizando aí os desvios e concessões que se seguiram a Freud. Pelo diálogo acurado com a literatura psicanalítica corrente, ele contrastou certas tendências, certa situação então vigente, com o que constituiria a sega cortante da verdade do campo aberto por Freud. Se a orientação que encontramos na fundação da Escola de Lacan, em seu endereçamento aos analistas, pode ser reportada aos primeiros Seminários, em contrapartida estava já posicionado, de modo inaugural em seu ensino, o horizonte $\mathrm{da}$ formação: “é sempre em função da questão o que fazemos quando fazemos análise? que esse comentário de Freud foi trazido aqui por mim" (Lacan, 1953-54/1986, p. 19). Sendo essa a questão de que parte, se ela constitui a divisa da leitura que Lacan realizará da obra de Freud, a precedência da experiência freudiana assume para Lacan (1953-54/1986, p. 129) o estatuto de um método.

Desde que esse ponto foi colocado, vocês puderam se aperceber, muitas coisas se orientam e se esclarecem, mas muitos paradoxos e contradições aparecem. O mérito dessa concepção é justamente o de fazer aparecer esses paradoxos e essas contradições, que nem por isso são opacidades e obscurecimentos. É frequentemente, ao contrário, o que aparece harmonioso e compreensível que encerra alguma opacidade. E é, inversamente, na antinomia, na hiância, na dificuldade, que encontramos chances de transparência. É nesse ponto de vista que repousa nosso método e, eu espero, o nosso progresso também. 
Nessa citação, vemos que o retorno a Freud visa restituir a hiância a que respondem os paradoxos e contradições em sua obra, supostos serem sobrepujados pelos avanços dos que se seguiram a ele. Em uma perspectiva contrária, Lacan sustenta que a harmonização do pensamento freudiano implica opacidade, ao passo que é na persistência dessa hiância que algo transparece. Algo transparece do que constitui o objeto da Psicanálise, como podemos ver em uma crítica direta de Lacan (195455/2010, p. 202) a Heinz Hartmann, um dos principais representantes da Ego Psychology. ${ }^{1}$

Encontra-se, de autoria de Hartmann, esta confissão assaz cândida, segundo a qual as concepções de Freud não concordam, no final das contas, assim tão bem entre si, e que precisam ser sincronizadas. São justamente os efeitos desta sincronização do pensamento de Freud que tornam necessária uma volta aos textos. $\mathrm{Na}$ verdade, ela parece-me ter uma lastimável ressonância de um botar nos eixos. Para nós, não se trata de sincronizar as diferentes etapas do pensamento de Freud, nem sequer de pô-las em concordância. Trata-se de ver a que dificuldade única e constante respondia o progresso deste pensamento, constituído pelas contradições de suas diferentes etapas. Trata-se, através da sucessão de antinomias que este pensamento continua nos apresentando, dentro de cada uma destas etapas e entre si, de defrontarmo-nos com o que constitui, propriamente, o objeto de nossa experiência.

No Seminário sobre a ética da Psicanálise (Lacan, 1959-60/1991), esse ideal de harmonização, que aqui aparece criticado em sua

1 Corrente teórica da Psicanálise que enfatizou o desenvolvimento do eu e sua adaptação à realidade. incidência sobre a obra de Freud, aparecerá contraposto a uma tal perspectiva ética. Por exemplo, na indicação de que, depois de a experiência freudiana ter lançado luz sobre as origens paradoxais do desejo, com o caráter de perversão polimorfa da sexualidade infantil (Freud, 1905/1989), “uma propensão geral levou os psicanalistas a reduzir essas origens paradoxais para mostrar sua convergência em direção a um fim de harmonia" (Lacan, 1959-60/1991, p. 13, grifos nossos). No lugar da harmonia, Lacan associa, a essa origem paradoxal, a hiância que dizia perpassar o pensamento de Freud. Aqui, ela remonta a algo de inconciliável na via do desejo, com o que define o traçado de sua reflexão sobre a ética. Ainda no contexto de uma crítica ao que se infere, em termos éticos, da leitura então difundida da obra de Freud, ele interroga, no mesmo Seminário, se a perspectiva de nossa ação deve reduzir-se ao "ideal de uma harmonização psicológica" (Lacan, 195960/1991, p. 362).

Propomos, neste artigo, examinar nos primeiros Seminários de Lacan, naqueles que são anteriores ao Seminário sobre a ética, o que teria sido identificado em sua crítica à Psicanálise pósfreudiana, de modo recorrente, como desvios $e$ concessões com relação ao que fora legado pela experiência inaugural de Freud. Tendo por referência o esquadrinhamento assim proposto, situaremos, a partir do que configuraria desvio segundo a demonstração de Lacan, o que define, para ele, a verdade que a obra freudiana transmite. Essa verdade, reportada em seu método à experiência de Freud, constitui o parâmetro desde o qual se designaria o que constitui desvio ou concessão. Nesta análise, pretendemos verificar 
que a dimensão ética da Psicanálise, que veio a ser explorada por Lacan, já se encontra incluída na crítica à Psicanálise pós-freudiana, na qual não se trata meramente da denúncia de uma má leitura da obra de Freud. Buscamos identificar de que modo os fundamentos éticos introduzidos estruturalmente no Seminário livro 7 já se encontram antecipados no que sustenta a crítica de Lacan à Psicanálise pós-freudiana; crítica que tem, no retorno a Freud, seu método.

Retornando aos primeiros Seminários, vemos que a crítica à sincronização da obra de Freud inclui também suas traduções, nas quais Lacan (1953-54/1986, p. 51) ressalta haver “inexatidões singulares, que vão até os limites da impropriedade". $\mathrm{Na}$ via do que vimos abordando, ele afirma que essas últimas "vão todas no mesmo sentido, que é apagar as arestas do texto" (Lacan, 1953-54/1986, p. 51). Novamente, o que aparece aqui, na crítica ao modo como a obra de Freud foi assimilada pelos autores que se seguiram a ele, estende-se à interrogação sobre o que ela implicou em termos éticos. O mesmo termo aresta aparece no Seminário sobre a ética, quando Lacan (195960/1991) contrapõe, ao ordenamento do material da experiência analítica em termos de desenvolvimento ideal, a dura aresta do pensamento de Freud. Quanto ao desejo, que situava, em seu ensino, um núcleo paradoxal da subjetividade, eixo do desenvolvimento de uma experiência ética na Psicanálise (Lacan, 195859/2016), é dito agora que apresenta "certas arestas, um certo ponto de obstáculo, e é precisamente nisso que ocorre que a experiência freudiana complica a direção dada ao homem de sua própria integração" (Lacan, 1959-60/1991, p. 256 , grifo nosso).

Assim como Freud (1910[1909]/1970, p. 37), Lacan (1953-54/1986, p. 34) sustentou, como veremos, ser a resistência ao inconsciente que está na base da resistência à Psicanálise; no caso aqui em questão, na base da recusa dos próprios analistas ao que a experiência freudiana implicou. Em razão disso, propõe recorrer ao método analítico em seu empreendimento: “o que é que eu quero? - senão sair desse verdadeiro impasse, mental e prático, ao qual chega atualmente a análise", para o que "importa submeter a própria análise ao esquema operacional que ela nos ensinou" (Lacan, 195354/1986, p. 34). Quando percorremos os primeiros Seminários de Lacan, identificamos os temas que, segundo ele, teriam sido privilegiados no âmbito da Psicanálise pós-freudiana e localizariam os impasses reportáveis à recusa do que a experiência de Freud estabeleceu.

No âmbito deste artigo, a circunscrição do fundamento ético da crítica de Lacan se apoiará em sua discordância relativa a duas categorias que se destacavam no que constitui os cânones do que denomina Psicanálise pós-freudiana. Intitulamo-las, aqui, eu autônomo e objeto harmônico. Entendemos que o exame feito, a seguir, da crítica a essas duas categorias mostra que, em torno delas, gravitam os desvios cuja evidenciação permite a Lacan avançar na direção de uma formulação em termos éticos do que especifica a experiência freudiana. Nela se abona o que constituirá os eixos do que o empreendimento de Lacan virá a consolidar. A crítica ao eu autônomo alicerça a afirmação de um sujeito dividido, no que concerne à retomada, 
por ele, da subversão engendrada pelo inconsciente freudiano. Do mesmo modo, a crítica ao objeto harmônico encaminha a busca, ao longo de seu ensino, de um estatuto inédito para o objeto que a experiência da Psicanálise baliza.

\section{O Eu Autônomo}

Citando Hartmann, Loewenstein e Kris, o trio responsável pela Ego Psychology, Lacan (1953-54/1986, p. 191) afirma que a leitura dos textos de Freud, posteriores a 1920, foi marcada por uma extrema inabilidade. Com o que insiste no ano seguinte: "a obra de metapsicologia de Freud, posterior a 1920, foi lida às avessas, interpretada de maneira delirante pela primeira e pela segunda geração depois de Freud" (Lacan, 1954-55/2010, p. 21). Ele se reporta aí ao que diz concernir a uma loucura comum, a uma crença: "temos todos tendência a acreditar que nós somos nós" (Lacan, 1954-55/2010, p. 23). A isso se ligaria a ideia do eu autônomo da Ego Psychology (Hartmann, 1939/1958; Lowenstein, 1972) a interpretação de que, depois de 1920 , Freud teria restituído esse lugar ao eu. À condição de desconhecerem que Além do princípio do prazer (Freud, 1920/1996) é a “obra-pivô" (Lacan, 1954-55/2010, p. 23) desse período; que Freud não estava recuando, no que diz respeito ao $e$, da subversão promovida com a hipótese do inconsciente nas primeiras décadas. Trata-se antes, com a pulsão de morte, de um passo além; quanto à qual, por conseguinte, Lacan mostrará que a maioria dos analistas entregou os pontos.
O fato de não terem aberto mão da centralidade do eu é uma questão que implica, na leitura lacaniana, o próprio trabalho analisante. Diante da "insuficiência" (Lacan, 1953-54/1986, p. 191) deste, os autores pósfreudianos retornaram ao eu como função psicológica e em seu propósito de síntese. Contrariamente, assim, a Freud ter introduzido “a partir de 1920 as noções suplementares então necessárias para manter o princípio de descentramento do sujeito" (Lacan, 195455/2010, p. 22). Remontando, como dissemos, ao trabalho analisante, Lacan associa a centralidade então recomposta do eu ao que configuraria a Psicologia de todo mundo, não a experiência do inconsciente. Indo além, ele mostrará como o fenômeno alcançou a análise como técnica, sendo que essa entificação abrigou uma noção de eu em que passa a se apoiar o analista: "um eu que é preciso reforçar, [...] que não é suficientemente forte, [...] um eu que deve ser o aliado do analista, o aliado do eu do analista etc." (Lacan, 1954-55/2010, p. 98).

De um lado, portanto, a concessão à ideia de um eu autônomo, implicando recuar com relação à subversão promovida pela hipótese do inconsciente e extraviar-se quanto ao que acarreta a pulsão de morte. De outro lado, se tal concessão denuncia a própria resistência do eu, converte-se ainda em guia para a técnica. Essa ideia de um eu a ser reforçado, de uma parte do eu à qual o analista poderia se aliar, é comentada assim por Lacan (195455/2010, p. 98):

a ideia que é muito simples, simples como bom-dia, de que há coisas boas neste sujeitinho boa-praça, de que há 
uma esfera sem conflito onde a libido está neutralizada, deslibidinizada, onde a própria agressividade está dessagressivada. É como Arquimedes que se lhe dê seu pontinho fora do mundo e ele pode erguê-lo. Mas este pontinho fora do mundo não existe.

Esse suposto ponto de Arquimedes ${ }^{2}$ contraria, assim, o que a experiência inaugural de Freud teria estabelecido: que não há esse ponto fora do mundo, ou, como Lacan (196970/1992) desenvolverá a partir da teoria dos discursos, não há um mundo que não seja o que já se encontra sustentado pelo próprio discurso. $\mathrm{Na}$ medida em que se tem como elemento mediador este "eu verdadeiramente ideal, no pior sentido da palavra" (Lacan, 1955-56/1985, p. 191), que é a esfera não-conflitiva (Hartmann, 1939/1958), o analista passa a ter como guia uma norma coerente com o seu próprio eu. Lacan (1956-57/1995, p. 26) dirá que, nessa perspectiva, o fim do tratamento associa-se à identificação ao eu do analista, resultando em "um imperialismo da identificação". Quanto a isso, desde o primeiro Seminário, Lacan (195354/1986, p. 27) já alertava, interrogando se "O conjunto do sistema do mundo de cada um de nós [...] deve efetivamente, sim ou não, servir, na análise, de medida".

Quando sustenta que esse tratamento centrado no eu acarreta a identificação ao analista, Lacan (1953-54/1986, p. 214) pergunta, mais uma vez, "por que isso não funcionaria com o analista, já que é assim que se constitui o ego na existência". Ao que pondera que a

\footnotetext{
2 Arquimedes de Siracusa (287-212 a.C.) dizia que, se dessem a ele um ponto de apoio, conseguiria erguer a Terra. Ele descobriu a lei da alavanca, que implica localizar o ponto de equilíbrio entre dois corpos.
}

questão é saber se é isso o que Freud nos ensinou. Como afirmamos, a crítica de Lacan desloca-se da dimensão da eficácia, já que, como acaba de dizer, não haveria motivo para não funcionar. Sua ponderação aponta, em lugar disso, para a orientação ética derivada da obra de Freud. Essa indicação de que os tópicos sobre os quais incidiram a crítica de Lacan à Psicanálise pós-freudiana já incluíam o fundamento do que ele viria a propor em termos éticos, em associação à experiência de Freud, se fará explícita, no Seminário sobre a ética da Psicanálise, na crítica ao que deriva do apelo à noção de um eu autônomo. Ele pergunta ali, justamente quanto às metas "que se articulam à noção de refazer o eu do sujeito” (Lacan, 1959-60/1991, p. 253), se elas não comportam uma dimensão ética. E afirma que essa última é inadequada por referência aos parâmetros segundo os quais o problema ético é articulado por Freud.

\section{O Objeto Harmônico}

Assim como a crítica ao eu autônomo vem dar suporte à evidenciação de um sujeito descentrado a partir da subversão freudiana do inconsciente, a crítica à ideia de um "objeto harmônico", outro alvo privilegiado de Lacan (1956-57/1995, p. 25), pavimenta a exploração em seu ensino de um estatuto inédito para o objeto extraído da experiência instaurada por Freud. Ele dedica um Seminário às teorias da relação de objeto (Lacan, 1956-57/1995), no qual questiona se é fundado dar-lhes uma situação central na Psicanálise. Com isso, reitera o método que indicamos, ao examinar o que as proposições ali encontradas devem ou não ao 
próprio Freud: "é uma espécie de guia, e quase uma limitação técnica que nos impusemos aqui, partir do comentário freudiano" (1956-57/1995, p.12). Lacan mira, em sua crítica às teorias da relação de objeto, a começar por Karl Abraham (1927/1970), o recentramento da relação sujeitoobjeto em torno de um objeto ideal, terminal, adequado, que determinaria o ponto de chegada de tal relação.

De imediato, assevera que a experiência freudiana contradiz a suposição de um tal objeto, com a qual a análise se converteria em uma normalização da relação sujeito-objeto. Lacan (1956-57/1995, p. 35) acusa se tratar aí de um mito, se não nos esquecemos de que “jamais, em nossa experiência concreta da teoria analítica, podemos prescindir de uma noção da falta do objeto como central". A centralidade da falta do objeto, ressaltada como eixo fundamental do problema na obra de Freud, questiona o recurso a noções qualificadas por Lacan como "bastardas", noções que conjugam, em suas palavras, um "otimismo néscio", um "moralismo equívoco" e um "esquematismo grosseiro" (1956-57/1995, p. 268). Ele se refere aí ao suposto desenvolvimento das fases ditas pré-genitais da libido, que culminam na entificação de um objeto genital, que responderia pela ortopedia do eu.

Diante, portanto, de uma dificuldade que é de ordem interna na abordagem do objeto, Lacan (1956-57/1995, p. 60) afirma ser "singular que a partir daí tenhamos deslizado para uma noção harmônica do objeto". Vimos, no início do artigo, que no Seminário sobre a ética da Psicanálise ele fundamenta a crítica a essa meta de harmonização da Psicanálise na origem perverso-polimorfa da sexualidade infantil, tomada no sentido de uma dificuldade fundamental no estabelecimento do estatuto do objeto na Psicanálise. Quanto a isso, é essencial que, enfatizando o ponto de vista estrutural, Lacan (1953-54/1986, p. 150) tenha também, desde o início, condenado a ênfase posta em uma perspectiva desenvolvimental das teses de Freud: "na verdade, Freud insiste sempre exatamente no contrário, a saber, a conservação, em todos os níveis, do que se pode considerar como diferentes etapas". Em um comentário mais agudo, afirma:

A ideia de um desenvolvimento individual unilinear preestabelecido, comportando etapas que vão aparecendo cada qual por sua vez conforme uma tipicidade determinada, é pura e simplesmente o abandono, a escamoteação, a camuflagem, a denegação propriamente falando, e inclusive o recalque, daquilo que a análise trouxe de essencial". (Lacan, 1954-55/2010, p. 26)

Já no fim de seu ensino, com relação ao mal-entendido a que se prestaria o próprio texto de Freud, Lacan (1972-73/1985, p. 76) avalia: "isto é um deslize, um retorno ao trilho, esse trilho que chamo de desenvolvimento, e que é apenas uma hipótese de mestria". Trata-se de um deslize com relação ao que, no mesmo Freud, excluiria "toda referência ao que se poderia chamar uma relação madura - o mito da Psicanálise” (Lacan, 1953-54/1986, p.155). É justamente à maturação do objeto que se associa a visada do objeto genital, conforme Lacan (1959-60/1991, p. 362) retoma no Seminário sobre a ética da Psicanálise, avançando que se supõe chegar assim à "medida de uma relação 
justa com o real", a qual "comporta certamente uma implicação moral".

Deparamo-nos aí com a possível afinidade, quanto a qual alertamos no início, entre o que preconizam as doutrinas criticadas por Lacan e os procedimentos objetivantes da avaliação quantitativa no campo da clínica. Contra uma apreensão objetivada da noção de realidade, na qual culmina a ideia de um objeto harmônico, Lacan (1953-54/1986, p. 31) insistiu, desde o início, no fato de que o domínio da pesquisa em que Freud avançava "é o da verdade do sujeito", o que marcaria seu estilo distinto de outras pesquisas científicas, na medida em que tal domínio não é inteiramente redutível à objetivação.

Essa verdade antinômica à objetivação, e contrária à suposição de um objeto adequado, foi explorada por Lacan (1956-57/1995, p. 54) por meio do que Freud (1923/1976) introduziu nos termos da castração, o que veio a ser negligenciado pelos analistas com a rearticulação da falta do objeto a partir do nível da "frustração". Com a frustração, trata-se da noção objetivante do "que o outro não pode dar", noção que estaria "simplesmente ausente da obra de Freud" (Lacan, 1968-69/2008, p. 83). Já com a castração, trata-se da falha estrutural a que responde, como vimos, a impostura, segundo Lacan, de pretender sincronizar o pensamento freudiano.

\section{A Ética da Psicanálise}

Verificamos, até aqui, que o retorno a Freud distinguiu, no que se encontraria no cerne desta obra, a marca da transmissão do inédito na experiência por ele inaugurada. Lacan se reporta, como examinamos, a uma hiância da qual não quis saber a articulação da doutrina nos termos em que figurou no âmbito da Psicanálise pósfreudiana. Como foi indicado, com relação às noções de um eu autônomo e de um objeto harmônico, a crítica efetivada por Lacan já permitia entrever seu fundamento ético, no que se identifica o movimento de convergência para o que veio a articular no seminário que dedica à ética da Psicanálise (Lacan, 1959-60/1991). Anos mais tarde, ele comenta: "foi para fazer face às carências de um certo grupo que fui trazido a este lugar que em nada ambicionava: o de ter que nos interrogar, junto com aqueles que puderam me ouvir, sobre o que fazíamos em consequência dessa obra, e, para tanto, remontar a ela" (Lacan, 1967/2003, p. 361). Ao que acrescenta: “[...] não foi por acaso - essa idéia não ocorria a ninguém - que, nesse ano, o quarto antes que meu seminário no Sainte-Anne chegasse ao fim, julguei ter de nos assegurar da ética da psicanálise" (Lacan, 1967/2003, p. 361).

$\mathrm{Na}$ abertura do referido ano de seu seminário, Lacan (1959-60/1991, p. 9) afirmava ser o domínio da ética aquele que, mais do que qualquer outro, permite "colocar à prova as categorias através das quais, naquilo que lhes ensino, acredito dar-lhes o instrumento mais apropriado para salientar o que a obra de Freud e a experiência da psicanálise que dela decorre trazem-nos de novo". Ao fim do seminário, diz ter se tratado naquele ano da "questão de saber quais são as consequências éticas gerais que a relação com o inconsciente, tal como foi aberto por Freud, comporta" (Lacan, 1967/2003, p. 350). Ao se perguntar sobre a incidência, no 
domínio da ética, do que Freud inaugurara, Lacan reiterou, então, o princípio segundo o qual se deveria buscar, na própria experiência analítica, no que ela ensina, os termos para a formalização de uma resposta. Em suas palavras: "ao invés de trazê-la para um denominador comum, ao invés de fazê-la entrar nas categorias já estabelecidas, tentamos articulá-la em sua topologia, em sua estrutura própria” (Lacan, 1967/2003, p. 375).

Não seria o caso, assim, de referenciar uma ética da Psicanálise segundo um quadro geral do que a tradição do pensamento ético chegara a estabelecer. Trata-se, antes, do que a experiência da Psicanálise conjuga como uma novidade não remissível ao que até então se havia consolidado naquele domínio. Se a Psicanálise pós-freudiana procurou harmonizar o legado freudiano a domínios e categorias que lhe eram prévios, o propósito do retorno a Frend de Lacan apoiou-se, aqui, no pressuposto de que Freud "partiu de uma intuição inicial, central, que é de ordem ética", justificando "ser essencial valorizá-la para compreender nossa experiência, para animá-la, para não nos extraviarmos, para não a deixarmos se degradar" (Lacan, 195960/1991, p. 52). A própria retomada da metapsicologia freudiana por Lacan, eixo de seu ensino até ali, foi também associada a esse fundamento no Seminário sobre a ética da Psicanálise: "é porque podemos aí [na metapsicologia freudiana] encontrar o rastro de uma elaboração que reflete um pensamento ético" (Lacan, 1959-60/1991, p. 51).

Como vimos antes, os alvos da crítica de Lacan à Psicanálise pós-freudiana foram retomados nesse Seminário (Lacan, 1959-
60/1991, p. 253, p. 362). Em oposição àquela, ele valorizou, na metapsicologia de Freud, suas antinomias e paradoxos, os quais testemunhariam justamente a hiância que a experiência delineia. As manobras que visavam à harmonização da obra de Freud, criticadas por Lacan, estariam relacionadas à prevalência de determinados ideais, aos quais a Psicanálise passaria a estar conciliada. Ao se interrogar sobre a ética da Psicanálise, o contraponto lacaniano traduz-se agora assim: “a questão ética, uma vez que a posição de Freud nos faz progredir nesse domínio, articula-se por meio de uma orientação ao real" (Lacan, 1959-60/1991, p. 21). Dita orientação ao real situa a impossibilidade de se conciliar com os ideais. O que era valorizado na obra de Freud quanto a seu valor de transmissão, em contraste com o aplainamento representado pelo que Lacan criticava na Psicanálise pós-freudiana, declina-se como uma novidade inserível no domínio ético, interpelando o entendimento de que seus desdobramentos convergiriam para o registro do que constitui os ideais.

É apontada, então, uma orientação ao real na qual Lacan $(1975-76 / 2007$, p. 128) insistirá posteriormente, concluindo que "é na medida em que Freud fez verdadeiramente uma descoberta - supondo-se que essa descoberta seja verdadeira - que podemos dizer que o real é minha resposta sintomática". Essa orientação, que o próprio autor designa como sua resposta singular ao que o campo aberto por Freud enceta, encontramos enraizada, no Seminário de 1959-60, na exploração da temática do desejo, em que se apoiou a interrogação sobre a incidência da Psicanálise no terreno da ética. 
Justamente porque se parte da ausência de harmonia, da impossibilidade de um objeto ideal, o desejo veio a constituir ali o eixo de tal problematização, pois, nos termos em que vinha sendo perscrutado no ensino de Lacan, situava justamente esse elemento inconciliável demarcado pela experiência analítica:

Com efeito, o ponto em que estamos chegando não é outro senão o do desejo e o que dele se pode formular a partir de nossa experiência [...].

Ainda que aí seja o centro do que Freud nos convida a entender no fenômeno da doença mental, é algo que em si só é tão subversivo que só se pensa em dele se afastar. (Lacan, 1954-55/2010, p. 299)

O desejo nos interessa no mais alto grau por uma dupla razão. Por um lado, lidamos com este desejo em nossa prática [...]. Por outro lado, é claro que o pensamento freudiano partiu desses paradoxos. Em particular no que diz respeito ao desejo [...]. Seria, realmente, lamentável esquecer isso em nossa tentativa de unificação ou de redução, quando lidamos com as teorias mais ingenuamente intuitivas a que se refere a psicanálise de hoje. (Lacan, 195657/1995, p. 167)

Diante da questão de como conceber uma ética não referida a ideais, a um objeto ideal, o desejo não poderá ser, portanto, uma solução ao problema, mas sim o que se encontra talhado, naquele momento, a situá-lo. Como vemos Lacan (1958/1998, p. 621) adiantar em $A$ direção do tratamento e os princípios de seu poder: "cabe formular uma ética que integre as conquistas freudianas sobre o desejo".

Se há uma ética da Psicanálise, ele dirá então no Seminário: "é na medida em que, de alguma maneira, por menos que seja, a análise fornece algo que se coloca como medida de nossa ação" (Lacan, 1959-60/1991, p. 374, grifos nossos). Associar o desejo à medida da ação é, por consequência, compor essa última com o que prepondera de paradoxos, arestas, dificuldades de ordem interna na Psicanálise. Nas palavras de Lacan (1959-60/1991, p. 378): “o reviramento que comporta nossa experiência situa no centro uma medida incomensurável, uma medida infinita que se chama desejo". Ao escolher, como padrão de revisão da ética, "a relação da ação com o desejo que a habita" (Lacan, 1959-60/1991, p. 375), é sustentado, portanto, o lugar de um elemento incomensurável no que deriva da experiência analítica.

Vemos, assim, que a revisão da ética estabelecida por Lacan segue a mesma direção instituída em sua crítica à Psicanálise pós-freudiana, balizada pelo retorno a Freud: sustentar-se no que decorre da estrutura própria à experiência, em lugar de se conciliar com as categorias comuns. Foi o que se deu, conforme analisamos, ao tomar, como alvo da crítica, a promoção no âmbito da doutrina psicanalítica de noções como a de um eu autônomo e a de um objeto harmônico. Em ambos os casos, estar-se-ia ajustando a Psicanálise a determinados parâmetros ideais, ao passo que Lacan preconiza que a verdade da obra de Freud vincula-se antes à insistência do que haveria de inconciliável. Trata-se da medida incomensurável, da medida infinita apontada por Lacan. Situá-la no cerne da experiência analítica é erigir um obstáculo basilar ao método preconizado no modelo de avaliação a que aludimos antes, bem como à ferramenta estatística por ele prescrita. 
Se é o desejo que demarcou, no Seminário livro 7, esse ponto desde o qual se concebe uma ética não referida aos ideais, mas orientada ao real, tal orientação vem a prosseguir no ensino de Lacan. O exame da ética da Psicanálise traçou, no horizonte do desejo, um gozo paradoxal, o qual veio a constituir o campo privilegiado do que o autor seguiu explorando. Ao adentrar as origens paradoxais do desejo, instituiu-se a antítese à concepção de um ethos que comportasse harmonia e conciliação. Mas, de modo correlato, ao penetrar no campo do gozo, a própria referência ética, estando a ele relacionada (Lacan, 1966/2001, p. 12; 1967/2003, p. 367), passará a constar de modo mais pontual em Lacan.

No Seminário contemporâneo ao Ato de Fundação de que partimos no artigo, diante de sua "excomunhão" pela IPA, Lacan (1964/1988, p. 24) acusa a "recusa do conceito", em um contexto no qual o retorno a Freud já inclui um “ir além de Freud" (Miller, 1997, p. 20). A articulação dos conceitos fundamentais, naquele ano, situa essa hiância - a que até então se referira, na crítica à Psicanálise pós-freudiana como na interrogação sobre a ética - de um modo em que não se trata apenas do que estaria em Freud, mas do que o próprio Lacan assume avançar como direção. Mais tarde, o que figurava como novidade na ética da Psicanálise será avocada como a emergência de um novo discurso (Lacan, 1968-69/2008). Entre esses diferentes momentos, a indagação sobre $\mathrm{O}$ objeto da Psicanálise persiste, com o objeto a vindo a conjugar causa de desejo (Lacan, 196263/2005, p. 113) e gozo (Lacan, 1968-69/2008, p. 16).
Assim se articula, no âmbito mesmo do objeto, a dimensão de algo que contraria o ideal cientificista de objetivação. Mesmo a verdade, noção que, como vimos, Lacan opunha em Freud a uma deriva objetivante da Psicanálise, convergirá para o que o objeto $a$ atesta, "por não haver no campo do Outro a possibilidade de uma consistência completa do discurso" (Lacan, 1968-69/2008, p. 24). O campo do gozo, ao qual conduziu a interrogação sobre a ética e pelo qual enveredou o ensino de Lacan, veio a produzir um efeito de retorno sobre a ética (Vieira, 2001, p. 156). Nos termos de um bem dizer (Lacan, 1974/2003, p. 539), promovem-se as soluções contingentes e incomparáveis em relação à impossibilidade do emprego, no âmbito dessa experiência, de um procedimento que, indiscriminadamente aplicável, legitimasse a medida da eficácia.

\section{Referências}

Abraham, K. (1970). Teoria psicanalítica da libido: sobre o caráter e o desenvolvimento da libido. (C. M. Oiticica, Trad.). Rio de Janeiro: Imago. (Originalmente publicado em 1927).

Freud, S. (1989). Três ensaios sobre a teoria da sexualidade (Edição Standard Brasileira das Obras Psicológicas Completas de Sigmund Freud, Vol. 7, V. Ribeiro, Trad.). Rio de Janeiro: Imago. (Originalmente publicado em 1905).

Freud, S. (1970). Cinco lições de Psicanálise (Edição Standard Brasileira das Obras Psicológicas Completas de Sigmund Freud, Vol. 11, D. Marcondes, Trad.). Rio de Janeiro: Imago. (Originalmente publicado em 1910).

Freud, S. (1996). Além do princípio do prazer (Edição Standard Brasileira das Obras Psicológicas Completas de Sigmund 
Freud, Vol. 18, C. M. Oiticica, Trad.). Rio de Janeiro: Imago. (Originalmente publicado em 1920).

Freud, S. (1976). A organização genital infantil: uma interpolação na teoria da sexualidade (Edição Standard Brasileira das Obras Psicológicas Completas de Sigmund Freud, Vol. 19, J. O. A. Abreu, Trad.). Rio de Janeiro: Imago. (Originalmente publicado em 1923).

Hartmann, H. (1958). Ego Psychology and the Problems of Adaptation. New York: International Universities Press. (Originalmente publicado em 1939).

Inserm (2004). Psychotérapie - trois approaches évaluées. Paris: Éd. Inserm.

Lacan, J. (1986). O Seminário, livro 1: os escritos técnicos de Freud (B. Milan, Trad.). Rio de Janeiro: Jorge Zahar. (Originalmente publicado em 1953-54).

Lacan, J. (2010). O Seminário, livro 2: o eu na teoria de Freud e na técnica da Psicanálise (M. C. L. Penot, Trad.). Rio de Janeiro: Jorge Zahar. (Originalmente publicado em 1954-55).

Lacan, J. (1985). O Seminário, livro 3: as psicoses (A. Menezes, Trad.). Rio de Janeiro: Jorge Zahar. (Originalmente publicado em 1955-56).

Lacan, J. (1995). O Seminário, livro 4: a relação de objeto (D. D. Estrada, Trad.). Rio de Janeiro: Jorge Zahar. (Originalmente publicado em 1956-57).

Lacan, J. (1999). O Seminário, livro 5: as formações do inconsciente (V. Ribeiro, Trad.). Rio de Janeiro: Jorge Zahar. (Originalmente publicado em 1957-58).

Lacan, J. (1998). A direção do tratamento e os princípios de seu poder. In J. Lacan. Escritos (V. Ribeiro, Trad.). Rio de Janeiro: Jorge Zahar. (Originalmente publicado em 1958).

Lacan, J. (2016). O Seminário, livro 6: o desejo e sua interpretação (C. Berliner, Trad.). Rio de Janeiro: Jorge Zahar. (Originalmente publicado em 1959-60).
Lacan, J. (1991). O Seminário, livro 7: a ética da Psicanálise (A. Quinet, Trad.). Rio de Janeiro: Jorge Zahar. (Originalmente publicado em 1959-60).

Lacan, J. (2005). O Seminário, livro 10: a angústia (V. Ribeiro, Trad.). Rio de Janeiro: Jorge Zahar. (Originalmente publicado em 1962-63).

Lacan, J. (1988). O Seminário, livro 11: os quatro conceitos fundamentais da psicanálise (M. D. Magno, Trad.). Rio de Janeiro: Jorge Zahar. (Originalmente publicado em 1964).

Lacan, J. (2001). O lugar da Psicanálise na Medicina (Vieira, M.A., Trad.). Opção Lacaniana, 32, 8-14. (Originalmente publicado em 1966).

Lacan, J. (2003). Alocução sobre as psicoses da criança. In J. Lacan. Outros escritos (V. Ribeiro, Trad.). Rio de Janeiro: Jorge Zahar. (Originalmente publicado em 1967).

Lacan, J. (2003). Ato de fundação. In J. Lacan. Outros escritos (V. Ribeiro, Trad.). Rio de Janeiro: Jorge Zahar. (Originalmente publicado em 1964).

Lacan, J. (2008). O Seminário, livro 16: de um Outro ao outro (V. Ribeiro, Trad.). Rio de Janeiro: Jorge Zahar. (Originalmente publicado em 1968-69).

Lacan, J. (1992). O Seminário, livro 17: o avesso da psicanálise (A. Roitman, Trad.). Rio de Janeiro: Jorge Zahar. (Originalmente publicado em 1969-70).

Lacan, J. (1985). O Seminário, livro 20: mais, ainda (M. D. Magno, Trad.). Rio de Janeiro: Jorge Zahar. (Originalmente publicado em 1972-73).

Lacan, J. (2003). Televisão. In J. Lacan. Outros escritos (V. Ribeiro, Trad.). Rio de Janeiro: Jorge Zahar. (Originalmente publicado em 1974).

Lacan, J. (2007). O Seminário, livro 23: o sinthoma (S. Laia, Trad.). Rio de Janeiro: Jorge Zahar. (Originalmente publicado em 1975-76). 
Lowenstein, R. (1972). Ego Autonomy and Psychoanalytic Technique. The Psychoanalytic Quarterly, 41(1), 1-22.

Maleval, J. C. (2012). Étonnantes mystifications de la psychothérapie autoritaire. Paris: Navarin.

Miller, J.-A. (1997). Contexto e conceitos. In R. Feldstein, B. Fink \& M. Jaanus (Orgs.). Para ler o Seminário 11 (pp.15-28). Rio de Janeiro: Jorge Zahar.

Thurin, J.-M. (26-02-2004). À propos de l'expertive collective Inserm sur l'évaluation des psychotérapies, Récupéré le 09 Juillet, 2018, de http:/ / techniquespsychoterapiques.org.

Vieira, M. A. (2001). A ética da paixão: uma teoria psicanalítica do afeto. Rio de Janeiro: Jorge Zahar.

Recebido em: 22/3/2018

Aprovado em: 22/12/2018 